\title{
Studies on Yeast Metabolism
}

\section{FRACTIONATION AND MICRODETERMINATION OF CELL CARBOHYDRATES}

\author{
By W. E. TREVELYAN AND J. S. HARRISON \\ Research and Development Department, Distillers Co. Ltd., Epsom, Surrey
}

(Received 16 December 1950)

Direct measurement of the metabolic changes in the intracellular carbohydrate of yeast has usually been restricted to the determination of total hydrolysable carbohydrate, that is to say, of reducing power after acid hydrolysis of a cell suspension. The work of Pickett \& Clifton (1943), or of Fales \& Baumberger (1948), exemplifies this technique applied respectively to the aerobic and anaerobic metabolism of glucose by yeast. Clifton (1946) has reviewed studies in some of which indirect methods were used: variation in carbon content, dry weight, and opacity have all been taken as indices of polysaccharide synthesis. Nickerson (1949) has taken the increase of dry weight of yeast during the aerobic metabolism of glucose as measuring, not merely synthesis of cell carbohydrate, but even synthesis of a particular polysaccharide, glycogen. Yeast, however, contains several other carbohydrates (see, for example, Neuberg, 1946): e.g. mannan, trehalose, and a 1:3-glucan insoluble in dilute acid or alkali. Of these trehalose (Pigman \& Goepp, 1948), and glucan (Hassid, Joslyn \& McCready, 1941) are only hydrolysed by drastic treatment which, when applied to yeast, might cause destruction of less stable sugars, such as the pentose derived from nucleotides and nucleic acids. In consequence, the determination even of total hydrolysable carbohydrate would seem, in principle, unsatisfactory. Schemes for fractionation of some of the constituents of yeast, followed by determination of each as reducing sugar after hydrolysis have been described, the latest being that of Payen (1949). These procedures frequently require large amounts of material and are excessively time-consuming.

By determining carbohydrate colorimetrically with the anthrone reagent (Dreywood, 1946) we have been able to estimate the total carbohydrate of the yeast cell directly, and also to analyse separate fractions without lengthy hydrolysis. Fractionation was achieved by extracting the yeast with trichloroacetic acid, after which the extracted material was treated with alkali, and an alcohol precipitation carried out according to the method used by Good, Kramer \& Somogyi (1933) for the determination of glycogen in animal tissue. The residue from these extractions formed a third fraction. Application of paper chromatography enabled this empirical procedure to be related to the known carbohydrate constituents of yeast.

\section{EXPERIMENTAL}

\section{Separation of the fractions}

Fraction 1. Trichloroacetic acid extract. Trichloroacetic acid (TCA) is generally used to extract from yeast, inter alia, hexose phosphates (Macfarlane, 1936; Juni, Kamen, Reiner \& Spiegelman, 1948). At room temperature and icebath temperature $10 \%(w / v)$ TCA was found to extract

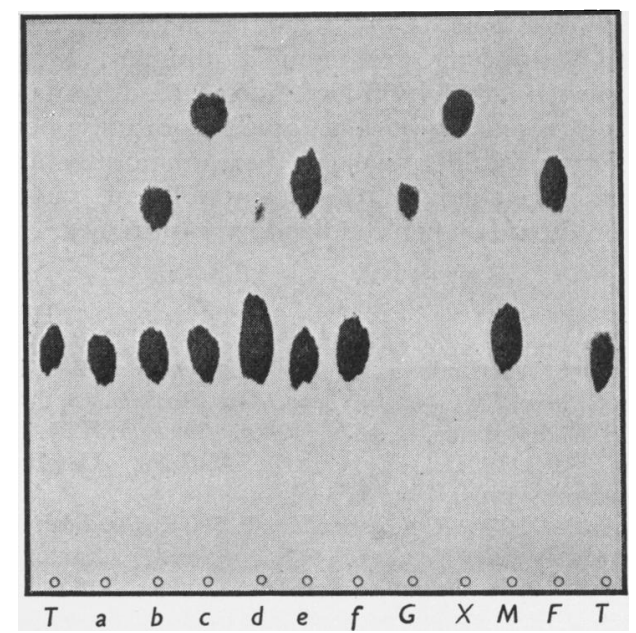

Fig. 1. Filter-paper chromatogram of TCA extract of yeast. $T$, trehalose, $R_{F}=0.29 ; a$, TCA extract of yeast; $b$, extract + glucose; $c$, extract + xylose; $d$, extract + maltose; $e$, extract + fructose; $f$, extract + trehalose; $G$, glucose, $R_{F}=0.48 ; X$, xylose, $R_{F}=0.59 ; M$, maltose, $R_{F}=0.32 ; F$, fructose, $R_{F}=0.50$. Sugar spots detected by alkaline silver reagent after developing with collidine.

much more carbohydrate from pressed baker's yeast than could be accounted for as phosphoric esters. In fact, when TCA extracts were examined by descending paper chromatography at room temperature, using the method of Partridge (1948), the only sugar detectable by the $\mathrm{AgNO}_{3}$ reagent previously described (Trevelyan, Procter \& Harrison, 1950) was trehalose (Fig. 1,a). Whatman no. 1 filter paper was used with s-collidine (Yorkshire Tar Distillers, purified by 
Br treatment as recommended by Partridge) saturated with water as the solvent. It will be seen from Fig. 1 that TCA does not interfere with the movement of sugars on the chromatogram.

Fraction 2. Alkali treatment. Following standard procedure (see Meyer, 1943) for the extraction of glycogen plus mannan from yeast, the TCA-extracted cells were digested with $30 \%(w / v)$ aqueous $\mathrm{KOH}$ on a water bath at $100^{\circ}$ for $15 \mathrm{~min}$., after which 2 vol. ethanol were added and the mixture was refrigerated overnight. The solid (fraction 3) was then centrifuged off, washed with $67 \%$ (v/v) ethanol, shaken with water, and again centrifuged. The supernatant,

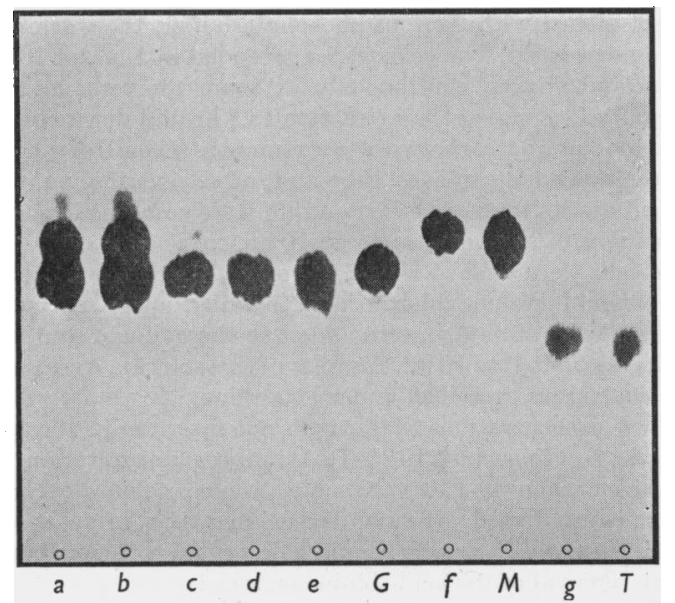

Fig. 2. Filter-paper chromatogram of carbohydrate fractions from yeast: $a$, hydrolysate of mannan + total glycogen, extracted by hot $2 \mathrm{~N}-\mathrm{H}_{2} \mathrm{SO}_{4}$ from TCA-extracted yeast; $b$, hydrolysate of mannan + alkali-extractable glycogen; $c$, hydrolysate of glycogen not extracted by alkali, but extracted by acid; $d$, hydrolysate of glucan after removing mannan and total glycogen with acid; $e$, hydrolysate of glucan after first removing alkalisoluble glycogen and mannan, and then acid-soluble glycogen; $G$, glucose, $R_{F}=0.47 ; f$, mannan hydrolysate; $M$, mannose, $R_{F}=0.54 ; g$, TCA extract; $T$, trehalose, $R_{F}=0 \cdot 36$. Sugar spots detected by alkaline silver reagent after developing with collidine.

containing the water-soluble carbohydrates, was made $2 \mathrm{~N}$ in $\mathrm{H}_{2} \mathrm{SO}_{4}$, hydrolysed for $2-3 \mathrm{hr}$. at $100^{\circ}$, and the residual acid was removed by adding excess $\mathrm{BaCO}_{3}$ and centrifuging. Chromatography of the solution showed the expected glucose and mannose; a faint third spot which was not identified also appeared (Fig. 2, b). To separate the mannan from the alkali digest Fehling's solution was added and the mannan-copper complex was centrifuged down, washed with $0.5 \mathrm{~N}-\mathrm{NaOH}$, dissolved in the minimum amount of $\mathrm{HCl}$, and the mannan reprecipitated with ethanol (Ling, Nanji \& Paton, 1925). The hydrolysed material showed a single spot on the chromatogram which was identified as mannose (Fig. 2, f). From Fig. 2 it will be seen that no appreciable amount of mannose is present in the yeast after hydrolysis of the separated carbohydrates, except in the mannan fraction.
Fraction 3. Residue. The washed residue from the alkali digestion was treated with $60 \% \mathrm{H}_{2} \mathrm{SO}_{4}$ which dissolved the carbohydrate. After standing for some time at room tem. perature the acid was diluted to about $5 \mathrm{~N}$ and heated at $100^{\circ}$ to effect hydrolysis. Chromatography showed that the hydrolysate contained glucose but no detectable mannose (Fig. 2,e). It seemed probable, however, that the glucose originated from a mixture of glycogen and glucan, since heating of the washed residue for $15 \mathrm{~min}$. in the water bath at $100^{\circ}$ with $2 \mathrm{~N}-\mathrm{H}_{2} \mathrm{SO}_{4}$ extracted a carbohydrate which on further hydrolysis with the same reagent gave glucose only (Fig. 2, c). In the light of further evidence presented in the Discussion the carbohydrate must be considered to be glycogen-like, whereas the residue from this treatment required hydrolysis with $60 \% \mathrm{H}_{2} \mathrm{SO}_{4}$ in the cold, and in other ways (see Discussion) showed the properties of glucan.

With modifications on these lines the above methods of fractionation were applied in the scheme of analysis described in the next section. In the subsequent part of this paper the carbohydrate obtained by extracting intact yeast with $10 \%(w / v)$ TCA is referred to as 'acid-soluble', that precipitated by Fehling's solution as 'mannan', the residue after treatment with hot $2 \mathrm{~N}-\mathrm{H}_{2} \mathrm{SO}_{4}$ as 'glucan', and the carbohydrate which is not accounted for in fractions 2 and 3 as mannan or glucan is called 'glycogen'. This nomenclature agrees with that generally accepted.

\section{Microdetermination of carbohydrate}

The analytical procedure of Morris (1948), in which colour is developed by means of the heat produced on mixing anthrone dissolved in $95 \% \mathrm{H}_{2} \mathrm{SO}_{4}$ with the aqueous test solution, proved unsatisfactory. Random fluctuations occurred, the mean of several determinations being reasonably reproducible, but single determinations unreliable. Consistent results were, however, obtained by mixing the reagents in the cold and developing colour by subsequent heating in the water bath. The method differs slightly from that recently described by Seifter, Dayton, Novic \& Muntwyler (1950), in that the anthrone is dissolved in acid of minimum strength (i.e. just sufficiently strong to prevent precipitation of anthrone during manipulation) in order to produce as little heat as possible on mixing the reagent with the carbohydrate solution.

Reagent. Conc. $\mathrm{H}_{2} \mathrm{SO}_{4}(500 \mathrm{ml}$.) was added to $200 \mathrm{ml}$. of water. Anthrone $(0.2 \mathrm{~g}$.) was dissolved in $100 \mathrm{ml}$. of the diluted acid by thorough shaking, any undissolved particles being removed from the surface with a pipette. The reagent should be prepared fresh daily.

Procedure. Anthrone reagent (5 ml. portions) was pipetted into 1 in. diameter Pyrex tubes, which were then cooled in ice water and $1 \mathrm{ml}$. of solution, containing 10 $100 \mu \mathrm{g}$. of glucose or equivalent carbohydrate, waslayered on top of the acid. When all tubes had been prepared they were removed from the bath and the contents mixed by rapid swirling : the temperature of the mixture rises slightly above room temperature. After covering with close-fitting bakelite bottle-tops the tubes were heated for exactly $10 \mathrm{~min}$. in a water bath, which must be boiling vigorously since the time and intensity of heating are important (Seifter et al. 1950). Bakelite lids were chosen because, owing to their physical properties, interference from condensation water was avoided. The tubes were then immediately plunged into running tap water and cooled for at least 2 min. It was found convenient to use a wire basket for holding the tubes. 
The green colour was read on the Unicam D.G. spectrophotometer at $620 \mathrm{~m} \mu$. against a $\mathrm{H}_{2} \mathrm{SO}_{4}$ blank (2 vol. $\mathrm{H}_{2} \mathrm{SO}_{4}: 1$ vol. water) using $\frac{3}{8}$ in. diameter tubes.

Standards. Glucose standard curves obtained by plotting colour measurement against amount of glucose, were satisfactorily linear between 25 and $100 \mu \mathrm{g}$., intermediate readings departing from those calculated from a $100 \mu \mathrm{g}$. standard by no more than $\pm 1 \mu \mathrm{g}$. A standard containing $100 \mu \mathrm{g}$. of glucose, together with a distilled water blank, was included in each batch of tubes. The standard was prepared daily from a $0.1 \%(w / v)$ solution of glucose in saturated benzoic acid. Mannose gives only $55 \%$ of the colour produced by an equal amount of glucose, and hence, if a measure of the amount of mannan, as such, is required it is preferable to include a mannose standard in the appropriate batch. For biochemical studies we find it convenient to express all constituents in terms of glucose. Reproducibility is good, the mean difference between parallel determinations on any of the fractions from a given yeast suspension being about $1 \%$.

The scope of the anthrone reaction, and its connexion with carbohydrate structure, has been dealt with by Sattler \& Zerban (1948). We find that pentoses, free or combined as in ribonucleic acid or adenosinetriphosphate, give a colour after about $3 \mathrm{~min}$. heating, which fades rapidly after this time (cf. Seifter et al. 1950). However, some residual absorption at $620 \mathrm{~m} \mu$. is always found. Seifter and co-workers have dealt with interference from certain non-carbohydrate compounds; one other important interfering substance likely to be present in fermentation studies is hydrazoic acid. In $2.5 \times 10^{-3} \mathrm{M}$ azide the colour given by $100 \mu \mathrm{g}$. of glucose is only one-third of normal, an effect which is not surprising in view of the wide range of organic compounds attacked by $\mathrm{HN}_{3}$ in the presence of mineral acid (Schmidt reaction: see Wolff, 1946). The $\mathrm{HN}_{3}$ was removed by $5 \mathrm{~min}$. aeration of samples which had been acidified with $\mathrm{H}_{2} \mathrm{SO}_{4}$. In general, we have found that oxidizing compounds have a profound effect on the anthrone reaction, whereas reducing substances such as $\mathrm{SO}_{2}$ or $\mathrm{SnCl}_{2}$ appear to have little effect. Some evidence has been obtained suggesting that the enol form of anthrone is the effective reagent.

\section{Carbohydrates of yeast : application of fractionation procedure}

The procedure described was worked out for the analysis of a $0.5 \%$ suspension of yeast in water or buffer, as used by us in manometric experiments, but it can easily be adapted to suit other requirements. Throughout this work analyses are based on the original weight of yeast used in the fermentation experiments (see below), because the conditions were such that, although there was no significant increase in cell numbers, changes occurred in the dry weight of the yeast due to synthesis or utilization of intracellular carbohydrate. Thus $0.5 \%$ suspension refers in all cases to a concentration equivalent to $0.5 \mathrm{~g}$. of pressed yeast (24-26\% dry matter at the commencement of the test) suspended in a total volume of $100 \mathrm{ml}$. When centrifuging small quantities (about $10 \mathrm{mg}$.) of yeast the cells sediment much better from potassium phosphate or phthalate buffer $(0.067 \mathrm{M}, \mathrm{pH} 4.5)$ than from water. The baker's yeast we have studied contains regularly about $80 \mu \mathrm{g}$. of total carbohydrate per $\mathrm{mg}$. as glucose (i.e. $1 \mathrm{mg}$. of yeast gives the same colour in the anthrone reaction as $80 \mu \mathrm{g}$. of glucose).

Total carbohydrate. The yeast suspension was diluted to
$1 \mathrm{mg} . / \mathrm{ml}$.: if the analysis was not to be performed at once, the dilution was made with $\mathrm{H}_{2} \mathrm{SO}_{4}$ to a final concentration of $0 \cdot 1-0.5 \mathrm{~N}$ to prevent metabolic change. Analysis was carried out as described under Procedure above. When material was limited, instead of adding $1 \mathrm{ml}$. of suspension directly, a smaller volume, say $0.2 \mathrm{ml}$., was added to the anthrone reagent, followed by $0.8 \mathrm{ml}$. of water. On mixing the anthrone reagent and yeast suspensions a slight turbidity was noticeable, but this disappeared on heating.

Extracellular sugar. Samples $(a) 2 \mathrm{ml}$. and $(b) 4 \mathrm{ml}$. of the $0.5 \%$ yeast suspension were centrifuged in $15 \mathrm{ml}$. roundbottomed tubes and $1 \mathrm{ml}$. samples of the supernatant were used undiluted for analysis as described under Procedure.

Acid-soluble sugar. The cell residues from tubes $(a)$ and $(b)$ were washed with $2 \mathrm{ml}$. of phosphate buffer, the washings being discarded. The cells were suspended in $1 \mathrm{ml}$. of $10 \%$ TCA and shaken continuously at room temperature for $30 \mathrm{~min}$. Prolonging the extraction to $3 \mathrm{hr}$. did not increase the amount of carbohydrate extracted. Then $1.5 \mathrm{ml}$. of water was added to each tube and, after centrifuging, the supernatants from tubes $(a)$ and $(b)$ were combined by decanting into a single stoppered $10 \mathrm{ml}$. measuring cylinder. The cells were washed with $2 \mathrm{ml}$. of water because residual TCA would produce chloroform in the subsequent treatment with alkali. Washings were added to the cylinder and the contents diluted to $10 \mathrm{ml}$. Samples of this solution were used for analysis as described under Procedure.

Low concentrations of TCA do not interfere in the anthrone reaction, but $10 \%$ TCA induces precipitation of anthrone when the tubes are cooled, though colour development is unaffected. If much larger quantities of yeast are used, the extraction step should be repeated to ensure complete removal of the acid-soluble material.

Mannan. To tube (a) $0.5 \mathrm{ml}$. of $30 \% \mathrm{KOH}$ was added, the tube was covered loosely with a glass stopper, and heated for $30 \mathrm{~min}$. on the water bath at $100^{\circ}$. After cooling to about $40^{\circ}, 0.5 \mathrm{ml}$. of Fehling's solution was added, and on shaking the mannan-copper complex flocculated. This was allowed to stand for some time, and was then centrifuged, washed with $1 \mathrm{ml}$. of $0.5 \mathrm{~N}-\mathrm{NaOH}$, using a glass rod to break up the precipitate, and recentrifuged. After draining off the liquid 1 drop of $6 \mathrm{~N}-\mathrm{HCl}$ was added to the precipitate, followed immediately by $1.4 \mathrm{ml}$. of water. Copper was dissolved and the precipitate became colourless; $1.4 \mathrm{ml}$. of ethanol was then added. After mixing and standing overnight in the refrigerator the solid was centrifuged and washed with $2 \mathrm{ml}$. $50 \%(v / v)$ ethanol. Washings were discarded and the tube drained. The remaining drop of ethanol was removed by standing the tube in a water bath at $100^{\circ}$ for 1 min. and aspirating air through the tube. A reagent (5 ml.) consisting of a suspension of about $0.1 \% \mathrm{BaSO}_{4}$ in $0.04 \mathrm{~N}-\mathrm{H}_{2} \mathrm{SO}_{4}$ was added and the tube was stoppered and vigorously shaken. On centrifuging the $\mathrm{BaSO}_{4}$ assisted complete sedimentation of the insoluble material. The supernatant contained the mannan and was analysed without further treatment as described under Procedure.

It should be noted that the cell debris still contains glycogen (see above), and therefore, if larger quantities of yeast are used for analysis, it is preferable to separate the $30 \%$ KOH extract in tube (a) from the residue before the copperprecipitation step. However, quantitative studies show that this portion of the carbohydrate remains insoluble throughout the procedure.

Glycogen plus mannan. The contents of tube (b) were heated with $\mathrm{KOH}$ as described for the estimation of mannan, 
and $1.4 \mathrm{ml}$. of ethanol were added to the hot mixture. Shaking caused precipitation of the polysaccharides, and the tube was then immersed in the water bath at $100^{\circ}$ until the ethanol began to boil. The tube was placed in the refrigerator overnight, after which it was centrifuged, the supernatant was discarded, and the solid washed with dilute ethanol as in the mannan determination. $2 \mathrm{~N}-\mathrm{H}_{2} \mathrm{SO}_{4}(2 \mathrm{ml}$.) was added and the tube was heated on the water bath at $100^{\circ}$ for 15-30 min. After cooling, $3 \mathrm{ml}$. of the $\mathrm{H}_{2} \mathrm{SO}_{4}: \mathrm{BaSO}_{4}$ reagent were added. The supernatant after centrifuging was poured into a $10 \mathrm{ml}$. cylinder, the residue was washed by resuspension in water and centrifuging, and the combined supernatants were made to $10 \mathrm{ml}$. This solution contained mannan, together with glycogen extractable by alkali, and that part of the glycogen not extracted by alkali but dissolved from the cell residue by acid. Total glycogen was measured by difference between this and the mannan figure.

If the $\mathrm{H}_{2} \mathrm{SO}_{4}$ extraction step is omitted, the alkaliextractable glycogen may be similarly determined after treating the ethanol-precipitated polysaccharides directly with the $\mathrm{H}_{2} \mathrm{SO}_{4}$ reagent as in the mannan determination or, more easily, by measuring the carbohydrate in the alkali digest directly by the anthrone reaction after diluting with water and centrifuging.

Glucan. The mixture of $\mathrm{BaSO}_{4}$ and cell residue remaining was well drained, and $4 \mathrm{ml}$. of anthrone reagent were added, agitating well with a glass rod which was splayed out at the end. After centrifuging, the supernatant containing the glucan was poured off into a dry tube and $1 \mathrm{ml}$. was mixed with $4 \mathrm{ml}$. of anthrone reagent, cooled, and colour developed after mixing with $1 \mathrm{ml}$. of water.

\section{Application to fermentation studies}

The procedure outlined above works well when the yeast suspension is not actively fermenting. If it is desired to analyse samples which have just been withdrawn from active fermentation, the danger of change in composition during the repeated washing necessary to remove external fermentable sugar is always present. It has been found possible, when glucose is being used as substrate, to stop the fermentation by adding TCA, and thus to obtain an acid-soluble extract containing trehalose, any sugar phosphates present, and residual glucose. The phosphoric esters are generally present in quite minute amounts (Macfarlane, 1936) and may be disregarded in the present scheme of analysis. The glucose may then be removed by hypobromite oxidation, when the trehalose remaining is directly determined. (For consideration of such oxidations see Pigman \& Goepp, 1948.)

Removal of glucose. To about $5 \mathrm{ml}$. of TCA extract, $5 \mathrm{~N}-\mathrm{NaOH}$ was added until neutral to phenolphthalein (external indicator: phenolphthalein produces a strong orange colour with $\mathrm{H}_{2} \mathrm{SO}_{4}$ in the anthrone reaction), then $0.5 \mathrm{ml}$. of saturated bromine water, followed by $1 \mathrm{ml}$. of $0.5 \mathrm{~N}-\mathrm{NaOH}$. After $15 \mathrm{~min}$. incubation at $30^{\circ}, 0.2 \mathrm{ml}$. of bromine water was added and incubation was continued for a further $15 \mathrm{~min}$. The mixture was acidified with $0.5 \mathrm{ml}$. of $4 \mathrm{~N}-\mathrm{H}_{2} \mathrm{SO}_{4}$, made to $10 \mathrm{ml}$. and excess bromine was removed by aeration. This treatment completely removed at least $4 \mathrm{mg}$. of glucose. Trehalose was determined on the solution.

\section{RESULTS}

An idea of reproducibility of the analyses obtained in actual fractionations can be obtained from Table 1 where two pairs of results are given. In Table 1 , column $A$, results are given for a fractionation after incubation of $10 \mathrm{mg}$. of yeast for $2 \mathrm{hr}$. at $30^{\circ}$ in $0.067 \mathrm{M}-\mathrm{KH}_{2} \mathrm{PO}_{4}$ : column $B$ gives results obtained in a separate experiment with $10 \mathrm{mg}$. of the same yeast. Columns $C$ and $D$ give the results of two experiments after similar incubation of $10 \mathrm{mg}$. of yeast in the presence of $2 \mathrm{mg}$. of glucose. The values obtained in the fractionation of successive yeast samples agree well, the mean difference being $10 \mu \mathrm{g} . / 10 \mathrm{mg}$. yeast. The maximum difference of $40 \mu \mathrm{g}$. occurs in the total carbohydrate figures, in these examples, and represents a percentage variation from the mean of about $\pm 3 \%$. The sum of the separate fractions is in all cases rather less than the total determined directly.

\section{Table 1. Carbohydrate analyses of fractions obtained from yeast}

(Columns $A$ and $B$ are fractionations from two experiments in each of which $10 \mathrm{mg}$. of a sample of pressed baker's yeast ( $25 \%$ dry matter) was incubated for $2 \mathrm{hr}$. at $30^{\circ}$ in $0.067 \mathrm{M}-\mathrm{KH}_{2} \mathrm{PO}_{4}$. Columns $C$ and $D$ are from similar fractionations where $2 \mathrm{mg}$. of glucose was added to the medium.)

\begin{tabular}{lrrrr} 
& \multicolumn{4}{c}{ Carbohydrate } \\
$\quad$ & \multicolumn{1}{c}{ Fraction } & \multicolumn{1}{c}{$B$} & $C$ & $D$ \\
Total carbohydrate & 830 & 790 & 1198 & 1160 \\
Extracellular & 5 & 11 & 51 & 49 \\
Acid-soluble & 233 & 226 & 246 & 246 \\
Mannan & 190 & 190 & 229 & 224 \\
Glycogen & 175 & 174 & 381 & 387 \\
Glucan & 158 & 159 & 176 & 171 \\
Sum of fractions & 761 & 760 & 1083 & 1077
\end{tabular}

Analyses of the alkali-soluble portion (fraction 2), of mannan, and of glycogen (after dilute acid treatment) showed that only $70 \%$ of the glycogen was extracted by alkali. In $10 \mathrm{mg}$. of unfermented yeast the $190 \mu \mathrm{g}$. g]ucose equivalent of mannan represents $346 \mu \mathrm{g}$. of mannose, giving a total carbohydrate value of some $96 \mu \mathrm{g}$. of hexose per mg., or about $38 \%$ of the total dry matter. The actual weight of di- and poly-saccharide would, of course, be somewhat less.

\section{DISCUSSION}

The methods described for the fractionation of yeast carbohydrates are essentially empirical, although based on the accepted techniques for separating these compounds; but they give satisfactorily reproducible results, and have been applied successfully to a study of yeast fermentation presented in a further communication (Trevelyan, Gammon, Wiggins \& Harrison, 1952). One striking observation in this work was that during fermentation of glucose the greatest variations occurred in fraction 3 (residue), suggesting that part of this fraction had biochemically the properties of glycogen (for reviews of the definition and chemistry of glycogen see Meyer, 1943; Bell, 1948). Furthermore, the amount of glucose-yielding material extracted by alkali varied with the proportion of yeast to alkali, although reproducible quantitative results were 
obtained by a given procedure. It would therefore appear that the glycogen may not have been completely extracted by the alkali treatment, particularly in view of the fact that various workers have shown that yeast glycogen is not homogeneous. Ling et al. (1925) refer to two forms of glycogen, one 'a constituent of the plasma' and readily extractable with water from dried yeast, and the other 'more intimately connected with the cell wall'. McAnally \& Smedley-Maclean (1937) showed that the residue after extraction with $60 \%$ potassium hydroxide contained magnesium and phosphate, and digestion of the residue with cold $\mathrm{N}$-hydrochloric acid rendered water-soluble a polysaccharide resembling glycogen. Jeanloz (1944) purified yeast glycogen which was separated by electrodialysis into two fractions, one soluble, the remainder $(73 \%)$ insoluble in water: some indication that yeast glycogen was partly phosphorylated was obtained. Alkali digestion was not used for preparation 'car il n'est pas possible d'effectuer le broyage total de toutes les cellules'.

In order to decide whether in our method the extraction of glycogen by alkali was complete a method for distinguishing between glycogen and glucan was necessary. Chromatography of hydrolysates does not, of course, differentiate. The periodate staining method of Hotchkiss (1948) was, therefore, used to follow the effect of alkali treatment, since he reported that yeast glucan, lacking an $\alpha$-glycol grouping except at the ends of chains, would probably give little colour in the staining reaction (cf. Barry \& Dillon, 1943). It was found that the yeast cell stained generally with the reagent, although a darker reticulated structure appeared in the cell interior. Extraction with trichloroacetic acid did not alter this appearance. Heating from $15 \mathrm{~min}$. to $3 \mathrm{hr}$. at $100^{\circ}$ with $30 \%(\mathrm{w} / \mathrm{v})$ potassium hydroxide gave a picture of a surrounding unstained cell wall, with some stained material remaining in the interior of the cell, but separated from the wall. This was presumably glycogen, since potassium hydroxide had been shown to extract the mannan readily. Heating of the cell residue for $15 \mathrm{~min}$. at $100^{\circ}$ with $2 \mathrm{~N}$-sulphuric acid, however, left a residue which did not stain. The acid extract contained a carbohydrate which, on further hydrolysis, gave glucose only (Fig. 2, c). The residue gave the anthrone reaction and hydrolysed to glucose, and hence was presumably glucan (Fig. 2, $d$ ). While this paper was in course of preparation, a publication by Bell \& Northcote (1950) appeared which provided confirmation of some of these findings. Whether the non-extractability of part of the glycogen by strong alkali denotes any sharp chemical or physiological difference, or whether alkali treatment, by depositing insoluble inorganic products inside the cell wall, mechanically prevents further diffusion of part of the glycogen, cannot be decided on the evidence so far obtained.

\section{SUMMARY}

1. The anthrone reaction has been adapted to give reproducible quantitative results, and has been applied to the determination of the total carbohydrate of baker's yeast.

2. An empirical procedure for fractionating the cell carbohydrates is described which may be applied to as little as $10 \mathrm{mg}$. of yeast $(2.5 \mathrm{mg}$. dry matter).

3. Paper chromatography and the periodate staining method of Hotchkiss have been used to relate the fractions to the known constituents of yeast, namely trehalose, glycogen, mannan and glucan.

4. Digestion with alkali $(30 \%$ potassium hydroxide) does not bring all the glycogen into solution, and a further treatment with acid is necessary.

5. A modification of the procedure is described which enables yeast cell carbohydrates to be determined in actively fermenting suspensions.

The authors thank the Directors of the Distillers Co. Ltd. for permission to publish this paper.

\section{REFERENCES}

Barry, V. C. \& Dillon, T. (1943). Proc. R. Irish Acad. 49 B, 177.

Bell, D. J. (1948). Biol. Rev. 23, 256.

Bell, D. J. \& Northcote, D. H. (1950). J. chem. Soc. p. 1944.

Clifton, C. E. (1946). Advanc. Enzymol. 6, 269.

Dreywood, R. (1946). Industr. Engng Chem. (Anal. ed.), 18, 499.

Fales, F. W. \& Baumberger, J. P. (1948). J. biol. Chem. 173, 1.

Good, C. A., Kramer, H. \& Somogyi, M. (1933). J. biol. Chem. 100, 485.

Hassid, W. Z., Joslyn, M. A. \& McCready, R. M. (1941). J. Amer. chem. Soc. 63, 295.
Hotchkiss, R. D. (1948). Arch. Biochem. 16, 131.

Jeanloz, R. (1944). Helv. Chim. Acta, 27, 1501.

Juni, E., Kamen, M. D., Reiner, J. M. \& Spiegelman, S. (1948). Arch. Biochem. 18, 387.

Ling, A. R., Nanji, D. R. \& Paton, F. J. (1925). J. Inst. Brew. 31, 316.

McAnally, R. A. \& Smedley-Maclean, I. (1937). Biochem.J. 31, 72.

Macfarlane, M. G. (1936). Biochem. J. 30, 1369.

Meyer, K. H. (1943). Advanc. Enzymol. 3, 109.

Morris, D. L. (1948). Science, 107, 254.

Neuberg, C. (1946). Ann. Rev. Biochem. 15, 435.

Nickerson, W. J. (1949). Experientia, 5, 202.

Partridge, S. M. (1948). Biochem. J. 42, 238. 
Payen, R. (1949). Canad. J. Res. 27, 749.

Pickett, M. J. \& Clifton, C, E. (1943). J. cell. comp. Physiol. 21, 77.

Pigman, W. W. \& Goepp, R. M. (1948). Chemistry of the Carbohydrates. New York: Academic Press.

Sattler, L. \& Zerban, F. W. (1948). Science, 108, 207.
Seifter, S., Dayton, S., Novic, B. \& Muntwyler, E. (1950). Arch. Biochem. 25, 191.

Trevelyan, W. E., Gammon, J. N., Wiggins, E. H. \& Harrison, J. S. (1952). Biochem. J. 50, 303.

Trevelyan, W. E., Proctor, D. P. \& Harrison, J. S. (1950). Nature, Lond., 166, 444.

Wolff, H. (1946). Organic Reactions, 3, 307.

\title{
Studies on Yeast Metabolism
}

\section{SYNTHESIS OF CELL CARBOHYDRATES DURING GLUCOSE FERMENTATION, AND ITS INHIBITION BY AZIDE}

\author{
By W. E. TREVELYAN, J. N. GAMMON, E. H. WIGGINS AND J. S. HARRISON \\ Research and Development Department, Distillers Co. Ltd., Epsom, Surrey
}

(Received 16 December 1950)

The major products of the fermentation of glucose by yeast are ethanol and carbon dioxide, but under certain conditions an appreciable amount of the glucose metabolized is accounted for by synthesis of cellular carbohydrate (see review by Clifton, 1946). The nature, extent and status of carbohydrate assimilation appear, however, to be still undecided. This is partly due to the use of indirect methods of judging the extent of carbohydrate synthesis using, for example, cell carbon content, dry matter, opacity or, in many cases, relying simply on manometric data. We have therefore examined the applicability of the method of analysis of yeast carbohydrates previously described (Trevelyan \& Harrison, 1952) to this problem, and further extended the method to an examination of the action of azide on fermentation, as this inhibitor has played an important part in assimilation studies.

\section{METHODS}

\section{Overall carbohydrate balance after fermentation}

Fermentations were carried out in an atmosphere of $\mathrm{N}_{2}$ at $30^{\circ}$ in the Warburg manometric apparatus. Carbohydrates were determined (Trevelyan \& Harrison, 1952) on the yeast suspension prior to fermentation, and on the suspensions remaining in the flasks after exhaustion of fermentable sugar.

Pressed baker's yeast (Distillers Co. Ltd.) was suspended in $0.067 \mathrm{M}-\mathrm{KH}_{2} \mathrm{PO}_{4}$ at $\mathrm{pH} 4.5$. The substrate, in most cases glucose, was added from the side arm of the Warburg flask after temperature equilibration, and $\mathrm{NaN}_{3}$, when used, was dissolved in the substrate solution. The solubility of $\mathrm{CO}_{2}$ in the medium was taken to be the same as in water, although according to graphical data presented by Van Slyke, Sendroy, Hastings \& Neill (1928) the solubility in $0.067 \mathrm{M}$ $\mathrm{KH}_{2} \mathrm{PO}_{4}$ at $38^{\circ}$ is about $3 \%$ less than in water. This variation hardly affects our figures.

In anaerobic yeast fermentation $\mathrm{CO}_{2}$ is formed by the decarboxylation of a $\mathrm{C}_{3}$ compound, pyruvic acid, which is split to give $\mathrm{CO}_{2}$ and a $\mathrm{C}_{2}$ moiety. The nature or fate of the latter does not affect the applicability of the Gay-Lussac equation, according to which $1 \mathrm{mg}$. of hexose is equivalent to almost exactly $250 \mu$ l. of $\mathrm{CO}_{2}$ at N.T.P. This value is used to calculate the 'hexose equivalent' of the $\mathrm{CO}_{2}$ measured manometrically. Carbohydrate analyses are expressed 'as glucose', i.e. in terms of the colour produced in the anthrone reaction by a standard glucose solution.

\section{Active fermentation studies}

In studies of the changes occurring during fermentation, samples were withdrawn at different stages of active fermentation of glucose by yeast, and the progressive variations with time of some constituents of the yeast suspension were determined. As explained in a previous paper (Trevelyan \& Harrison, 1952) all analyses are referred to the original weight of pressed yeast (24-26\% dry matter).

Procedure $A$. Yeast suspension (yeast suspension is defined in Part 1) and glucose solution were prepared separately and chilled in ice. When cold, equal volumes were mixed and $2 \mathrm{ml}$. of the mixture were dispensed into each of six $15 \mathrm{ml}$. centrifuge tubes. Air was rapidly displaced from the tubes by $\mathrm{N}_{2}$, and they were stoppered and shaken in a water bath at $30^{\circ}$. (For details of amounts of yeast and glucose, see under separate experiments.)

Procedure $B$. This procedure was used to study fermentation in the presence of $\mathrm{NaN}_{3}$. Portions $(1 \mathrm{ml}$.) of a yeast suspension were measured into centrifuge tubes, which were equilibrated at $30^{\circ}$ while nitrogen was passed through the tubes. Glucose-azide solution, previously brought to $30^{\circ}$, was added and the tubes were stoppered and shaken. At various times after the commencement of fermentation tubes were removed, immediately centrifuged, and residual glucose determined by the anthrone method (Trevelyan \& Harrison, 1952). In some experiments the ethanol content of the centrifugate was determined, using the microdiffusion method of Macleod (1949). Glycerol was estimated, after removing residual glucose by precipitation with $\mathrm{CuSO}_{4}$ and $\mathrm{Ca}(\mathrm{OH})_{2}$ according to Van Slyke (1917), by periodate oxidation and colorimetric determination of the resultant formaldehyde by the method described by Corcoran \& Page (1947) for the estimation of mannitol in physiological fluids. 